The Journal of the International Society for Oncodevelopmental Biology and Medicine

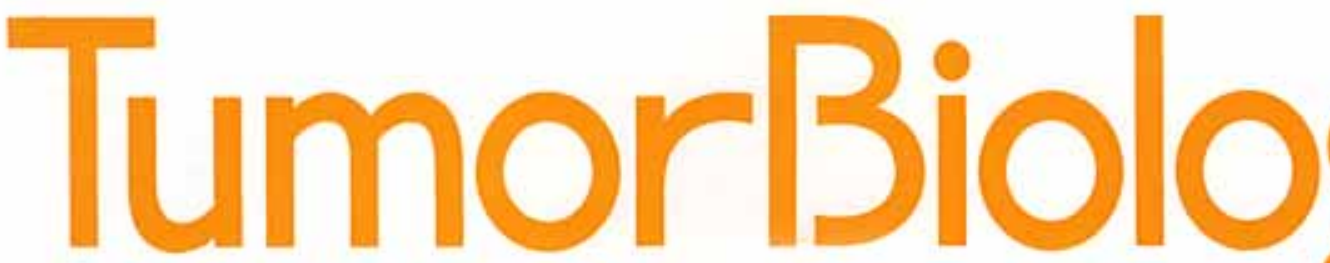

From

Basic Science

to

Clinical Application

\title{
From Tumor Biology to Clinical Oncology
}

The 26th Meeting of the International Society for Oncodevelopmental Biology and Medicine, ISOBM 1998

August 30-September 4, 1998

Umeá, Sweden

S. Karger

Medical and Scientific

Publishers

Basel - Freiburg

Paris + London

New York - New Delhi

Bangkok - Singapore

Tokyo $\cdot$ Sydney

\section{KARGER}


This issue contains the abstracts

From Tumor Biology to Clinical Oncology

The 26th Meeting of the International Society for

Oncodevelopmental Biology and Medicine, ISOBM 1998

Umeå, Sweden, August 30-September 4, 1998

and is not available online for technical reasons. 